\title{
O papel das instituições na trajetória econômico-social do Estado do Rio de Janeiro ${ }^{1}$
}

\author{
Mauro Osorio $^{2}$ \\ Maria Helena Versiani ${ }^{3}$
}

\begin{abstract}
RESUMO
A trajetória econômica, política, social e institucional da cidade e do Estado do Rio de Janeiro é o objeto privilegiado de análise deste artigo, que pretende também apontar os desafios existentes para a superação, no século XXI, do processo de decadência econômica vivenciado na região no período pós-1960.
\end{abstract}

Palavras-chave: Rio de Janeiro; economia regional; desenvolvimento socioeconômico.

\begin{abstract}
The trajectory of economical, political, social and institutional development of the city and state of Rio de Janeiro is the subject matter of analysis in this article, which aims to point out the existing challenges to overcome, in the XXI century, the process of economic decadence experienced in the region post-1960.
\end{abstract}

Keywords: Rio de Janeiro; regional economy; socioeconomic development.

\footnotetext{
${ }^{1}$ Registramos aqui nossos sinceros agradecimentos ao economista Pedro Américo de Almeida Ferreira, pelo cuidadoso trabalho de revisão deste artigo.

${ }^{2}$ Professor Adjunto do Departamento de Direito Social e Econômico da Faculdade Nacional de Direito da UFRJ e do Programa de Pós-Graduação em Direito da Universidade Federal do Rio de Janeiro. Doutor em Planejamento Urbano e Regional, pelo Instituto de Pesquisa e Planejamento Urbano e Regional da UFRJ. Email: mauroosorio@uol.com.br.

${ }^{3}$ Historiadora, vinculada ao Museu da República e integrante do grupo de pesquisa Observatório de Estudos sobre o Rio de Janeiro (UFRJ). Doutora em História, Política e Bens Culturais, pelo CPDOC/FGV. E-mail: m.versiani@globo.com
} 


\section{Introdução}

A cidade do Rio de Janeiro se construiu institucionalmente, desde a sua fundação, como um espaço de articulação nacional. Inicialmente, derivou o seu dinamismo econômico-social do fato de ser o principal porto brasileiro e centro militar e, posteriormente, de ser a capital da República e centro cultural, político e econômico do país - como sede do poder federal, centro financeiro nacional e sede de empresas públicas e privadas atuantes no território brasileiro e mesmo latino-americano.

Com essa trajetória singular, a cidade do Rio de Janeiro apresentou, até o início do século XX, o maior produto interno bruto (PIB) do país, como também o maior parque industrial. Contudo, dados do Censo de 1919 mostram que, naquele ano, o PIB industrial do Estado de São Paulo já superava o carioca e que então era o estado paulista que liderava o processo de crescimento econômico brasileiro.

Por outro lado, apesar da economia da cidade do Rio de Janeiro apresentar, no correr de todo século XX, uma progressiva perda de posição relativa, comparativamente a São Paulo, entre 1920 e 1960, o dinamismo econômico carioca ainda se mantinha próximo ao da média nacional. Isto porque, nesse período, a cidade ainda exercia a função de sede do poder federal, continuando assim a atrair e gerar investimentos. Carlos Lessa (2000:237-238) pontua essa questão da seguinte forma:

\footnotetext{
As décadas de 1920 a 1960 foram de prosperidade e de acumulação de prestígio no Rio de Janeiro. A cidade desdobrou-se em novos comportamentos e dimensões. (...) O Rio urbanizou-se em sintonia com esses novos tempos. Cabe sublinhar que foi sendo secundarizado, em termos de produção industrial, em relação a São Paulo. Desde a Primeira Guerra Mundial, São Paulo lidera a produção industrial e, apesar de crescer, o Rio vê a distância relativa das respectivas bases industriais ser ampliada, para não lembrar a espantosa diferença no campo agrícola. Porém, o Rio - concentrando serviços sofisticados, com o núcleo de comando do sistema bancário, sediando os escritórios centrais da maioria das grandes empresas, sendo o portal dos visitantes nacionais e estrangeiros, e alimentado por contínuas e crescentes injeções de gasto público - parecia ter assinado um pacto com a eterna prosperidade.
}

Além disso, também o antigo Estado do Rio de Janeiro - considerado por Lysia Bernardes (1964) uma região polarizada, do ponto de vista econômico, pela cidade do Rio - era cenário de importantes investimentos federais, como a instalação da Companhia Siderúrgica Nacional; a Fábrica Nacional de Motores; a Companhia Nacional de Álcalis; e 
a Refinaria Duque de Caxias. E, como lembra Carlos Lessa (2000:346), as decisões locacionais para tais investimentos estiveram relacionadas com a proximidade da antiga capital federal e também com a existência de uma tendência dominante, dentro do governo central, a favor da realização de um contraponto, no país, ao predomínio econômico paulista.

De fato, indicadores relativos ao PIB dos estados e regiões do Brasil mostram que, nos anos 1950, o território que abrange a atual região fluminense apresentava um crescimento médio percentual de 6,6\% ao ano, bastante próximo ao da Região Sudeste, de 6,7\% ao ano, e ao do total do Brasil, de 7,1\% ao ano (Pacheco, 1998:69).

Porém, a partir de 1960, com a transferência da capital federal para Brasília, a cidade do Rio de Janeiro - organizada desde a origem, como já dito, como porto e eixo de logística nacional, e que a partir da vinda da família real se consolida como centro de articulação nacional, do ponto de vista político, cultural, econômico e social - sofre um processo de fratura em sua dinâmica institucional, o mesmo ocorrendo com a Velha Província, ${ }^{4}$ que deriva sua lógica econômica, pós-ciclo cafeeiro, do dinamismo existente em seu núcleo econômico central - a cidade do Rio de Janeiro - e dos investimentos federais nela realizados até 1960 .

A trajetória econômica, política, social e institucional da cidade e do Estado do Rio de Janeiro é o objeto privilegiado de análise deste artigo, que pretende também apontar os desafios existentes para a superação, no século XXI, do processo de decadência econômica vivenciado na região no período pós-1960.

\section{Rio de Janeiro: história nacional e fratura na dinâmica institucional local}

Utilizando a conceituação de economistas institucionalistas, como Douglass North (1993), Geoffrey Hodgson (1997) e Thorsten Veblen (1934), que definem instituições como normas formais (leis e regulamentos) e informais (história, cultura, hábitos e rotinas), podemos afirmar que a dinâmica da cidade do antigo Estado do Rio de Janeiro, a partir da transferência da capital federal para Brasília, em 21 de abril de 1960, sofreu uma ruptura em seu marco institucional.

\footnotetext{
${ }^{4}$ Denominação costumeiramente dada ao antigo Estado do Rio.
} 
No mesmo sentido, podemos utilizar o marco teórico construído por Paul Krugman (Krugman, Fujita e Venables, 2002), quando o autor busca analisar a existência de diferenças marcantes nos níveis de desenvolvimento das regiões.

Krugman utiliza o conceito de linkages, proposto por Albert Hirschman, para afirmar que uma determinada atividade econômica pode gerar efeitos de encadeamento em um determinado território e, por conseguinte, rendimentos crescentes de escala. Além disso, incorpora o conceito de "causação circular cumulativa", de Gunnar Myrdall, para construir a ideia de que uma determinada região, a partir de dada diferenciação inicial que pode ser, por exemplo, a existência de um porto ou a ocorrência de algum fato histórico, mesmo que fortuito - poderia vir a desenvolver novas diferenciações, em relação a outras regiões.

Tal processo envolveria uma tensão entre forças centrípetas (que gerariam dinamismo para a região em foco) e forças centrífugas (que poderiam estimular a migração de investimentos para outras regiões). As forças centrípetas seriam, fundamentalmente, os efeitos de encadeamento que o investimento em uma determinada atividade geraria em outras; a formação de um mercado de trabalho com tal porte que permitisse que empregadores tivessem facilidade para encontrar trabalhadores - sobretudo trabalhadores com habilidades especializadas - e vice-versa; e também o que o autor denomina de "meras economias externas", ou seja, qualquer tipo de facilidade extra-firma gerada pela concentração territorial.

As forças centrífugas estariam relacionadas a questões como o esgotamento de fatores produtivos, como, por exemplo, o esgotamento de terras; o aumento do custo dos aluguéis; a carência de infraestrutura; e quaisquer formas de deseconomias externas, como a poluição, a violência etc.

Dessa forma, uma dada região poderia apresentar um dinamismo econômico próximo ou superior ao de outras regiões, no cenário da economia de um determinado país ou da economia mundial e, a partir de certo momento, por efeito da preponderância de forças centrífugas vis-à-vis às forças centrípetas, poderia sofrer uma "bifurcação" ou reversão desse dinamismo econômico-social.

Nessa perspectiva, pode-se afirmar que os territórios carioca e fluminense, por derivarem o seu dinamismo econômico centralmente da história de capitalidade da cidade 
do Rio de Janeiro, ${ }^{5}$ sofreram, a partir dos anos 1960, um processo de erosão da sua importância e do seu dinamismo econômico-social. O entendimento dessa questão, no entanto, não é realizado de forma imediata, pelos próprios cariocas e fluminenses, só ocorrendo nos anos 1980, com a inversão do processo de crescimento da economia brasileira e a crise fiscal que então se instaura, atingindo particularmente o Estado do Rio de Janeiro, pelo peso que o gasto federal ainda tinha na região. Dessa forma, até o final da década de 1970, viveu-se a doce ilusão de que a cidade do Rio de Janeiro teria assinado, nos dizeres de Carlos Lessa (2000:238), "um pacto eterno com a prosperidade."

A demora nessa percepção pode ser compreendida com base em um conjunto de fatores, a começar pela força da cultura de capitalidade no território carioca, construída a partir da histórica centralidade política, econômica e social do Rio de Janeiro no cenário nacional. Como sugere Douglass North (1993), uma determinada conformação institucional cria hábitos e rotinas arraigados, nos quais as questões de escolha se apresentam como algo regular, repetitivo e claramente evidente, de modo que cerca de 90\% de nossas ações em vida são realizadas de forma basicamente automática. É nessa perspectiva que se pode aferir que a cultura de capitalidade do Rio de Janeiro acaba por contribuir para que nessa região não ocorra, de forma imediata, a percepção da quebra da dinâmica institucional, ocorrida a partir de um fator "exógeno" (a mudança da capital federal para Brasília, em 1960).

No mesmo sentido, Geoffrey M. Hodgson (1997), partindo de pressupostos teóricos distintos e utilizando autores como Marx, Keynes e os institucionalistas americanos do final do século XIX e início do XX - Veblen, Commons e Mitchell ${ }^{6}$-, realiza conclusões, do ponto de vista do conceito de dinâmica institucional, bastante próximas às construídas por North, ${ }^{7}$ conforme se pode deduzir da seguinte passagem:

[Veblen] observou que as instituições têm uma qualidade de estabilidade e inércia e que tendem a manter e, portanto, a 'transmitir' as suas características importantes ao longo do tempo. As instituições são

\footnotetext{
5 Estamos utilizando aqui o conceito de "capitalidade" conforme proposto por Marly Silva da Motta (2001:24), quando, partindo da formulação teórica de Giulio Argan - arquiteto, historiador da arte e prefeito comunista de Roma (1976-1979) -, define as cidades-capitais como "o lugar da política e da cultura, como núcleo da sociabilidade intelectual e da produção simbólica, representando, cada uma a sua maneira, o papel de foco da civilização, núcleo da modernidade, teatro do poder e lugar de memória."

${ }^{6}$ Geoffrey Hodgson utiliza como referência básica os institucionalistas americanos citados. No entanto, em sua obra aparece com centralidade os trabalhos de Veblen quando este propõe que se troque, como paradigma econômico, a ideia do equilíbrio advinda da Física pela ideia da evolução, utilizando a Biologia como metáfora.

${ }^{7}$ A questão da existência de aspectos heterodoxos na formulação de Douglass North é pontuada no artigo de Ronaldo Fiani, Estado e economia no institucionalismo de Douglass North (Fiani, 2003).
} 
consideradas frutos e reforçadores dos processos de pensamento rotinizados, sendo partilhadas por um conjunto de pessoas numa dada sociedade. (Hodgson, 1997:276)

Geoffrey Hodgson afirma também que o institucionalismo compreende os indivíduos a partir do modo como estão situados e envolvidos em seu mundo social. Dessa forma, as suas funções e preferências não seriam dadas e fixas, mas sim construídas e reconstruídas socialmente, em um contínuo processo de adaptação e mudanças. Novamente citando Veblen, Hodgson (1997:10) ${ }^{8}$ escreve:

\begin{abstract}
Uma linha de ação habitual constitui uma linha habitual de pensamento e dá o ponto de vista através do qual os fatos e eventos são apreendidos e reduzidos a um corpo de conhecimento. As instituições criam e reforçam os hábitos de ação e pensamento: a situação de hoje molda as instituições de amanhã, através de um processo coercivo e seletivo, através da ação sobre a visão habitual do homem das coisas e dessa forma alterando ou fortificando um ponto de vista de uma atitude mental trazida do passado.
\end{abstract}

Ou seja, por um lado, conforme identificado por institucionalistas como Geoffrey Hodgson e Douglass North, uma determinada cultura influencia a conformação de certas formas de raciocínio e de percepção do mundo, podendo dificultar a compreensão imediata de uma mudança gerada a partir de um fator exógeno - no caso aqui em exame, as consequências advindas para o Rio de Janeiro, com a mudança da capital federal para Brasília em 1960.

Por outro lado, o fato da transferência da capital se acelerar somente a partir da década de 1970, ao lado do dinamismo apresentado pela economia brasileira no período 1968/1980, mascara a lógica que se inaugura com a mudança da capital, não se tendo a percepção de que, por exemplo, na década de 1970, o território que hoje abriga a cidade do Rio de Janeiro apresentava um crescimento industrial de apenas 173\%, contra um crescimento brasileiro em torno de $285 \%$ e, em Minas Gerais, em torno de 342\% (Rosa e Osorio, 1995).

\title{
2. Fragilidade do marco político-institucional local e suas consequências no pós-1960
}

Para uma análise da demora na percepção das consequências, para o Rio de Janeiro, da transferência da capital federal em 1960, deve-se levar em conta também o modelo

\footnotetext{
${ }^{8}$ Tradução de Alexandre Borges.
} 
institucional adotado para o Distrito Federal quando da implantação da República no Brasil. Ao se organizar a capital federal, na instauração da República, buscou-se constituíla de forma tecnocrática e conservadora, tendo como referência a cidade de Washington, ${ }^{9}$ capital dos EUA, procurando-se restringir ao máximo o espaço da política local - o que foi posteriormente confirmado na Constituição de 1946 e na Lei Orgânica do Distrito Federal de 1948. Assim, ficou definido que o prefeito do Distrito Federal seria nomeado pelo presidente da República e que, ao contrário das demais localidades brasileiras, as leis votadas pelos vereadores da capital, que fossem depois vetadas pelo prefeito, não retornariam à Câmara Municipal, mas sim seriam analisadas pelo Senado Federal.

$\mathrm{Na}$ verdade, o esforço de neutralizar a política local naquele território não era uma novidade da República. Desde 1834, quando ocorrera a separação institucional da capital da província fluminense visando à criação do Município Neutro, já se afirmava o entendimento de que a capital deveria constituir um espaço politicamente neutralizado, conforme demarcado por Carlos Lessa:

Para a federação sonhada pela República, o Rio como Município Neutro era perfeito para a transmutação em Distrito Federal. Desde 1834, a cidade estava separada da província fluminense. A Capital para a República deveria manter-se politicamente neutralizada. O prefeito, escolhido pelo presidente e submetido à aprovação pelo Senado, não é o chefe do poder executivo, independente de aprovação local. É um alto funcionário de confiança do presidente que pode demiti-lo ad nutum. (...) O Rio seria o 'fórum asséptico', guardião e depositário do pacto oligárquico, o lugar de construção do marco zero da República e a moldura para dignificar a Presidência. (Lessa, 2000:187-188)

A forma como se organizou a institucionalidade local da cidade do Rio de Janeiro - ao lado de sua história de capitalidade - influiu para que o debate e o jogo político local perdessem força na região, contribuindo assim para a conformação de um particular quadro de carência no tocante à reflexão local.

Desse modo, constituiu-se com força na cidade do Rio, conforme analisado por Marly Silva da Motta (2000; 2001), duas lógicas políticas. Uma bastante focada nas questões nacionais e radicalizada no que se refere à representação da cidade na Câmara Federal e no Senado - o que pode ser visto com clareza, por exemplo, no fato de disputarem o senado pelo Distrito Federal, em 1958, Afonso Arinos, prócer da UDN nacional e deputado por Minas Gerais, e Lutero Vargas, simbolizando o getulismo; ou no

\footnotetext{
${ }^{9}$ Sobre o assunto, ver Freire (2000) e Motta (2001).
} 
fato de, em 1962, terem participado da disputa pela representação da Guanabara no Senado, Juracy Magalhães, então governador da Bahia e liderança nacional da UDN, e Aurélio Viana, deputado federal por Alagoas e líder da esquerda nacionalista na Câmara dos Deputados. Já outra lógica, a da política local, seria determinada pela ausência de eleições diretas locais para prefeito e pelo pouco poder dos vereadores eleitos para interferir na vida da cidade. Veja-se, ainda, que, no período entre 1946 e 1960, as eleições para a representação federal na cidade do Rio de Janeiro/Distrito Federal se deram centralmente em torno de poucos partidos e com forte participação de líderes políticos que simbolizavam o debate nacional, ao passo que o jogo político local ocorreu de forma fragmentária e clientelista, num quadro de forte pulverização das agremiações partidárias. Nos anos 1950, por exemplo, enquanto a representação federal do Rio limitava-se a quatro partidos com dois ou mais membros eleitos, a representação local fracionava-se em onze partidos. Além disso, entre os quatro partidos, a representação federal se dava com forte centralização no PTB e na UDN, enquanto a representação do PSD carioca (maior partido do Congresso Nacional nos anos 1950, com posição mais centrista) limitava-se a um único parlamentar, tendo em vista o polarizado debate nacional, reproduzido com particular força no Rio de Janeiro, nesse período. O debate nacional era liderado, por um lado, por Getúlio Vargas, Leonel Brizola e João Goulart e, por outro, por Carlos Lacerda. E, ao contrário da lógica política nacional, a lógica política local teria menos peso e importância e ocorreria de forma marcadamente fragmentária. ${ }^{10}$

Assim, a forma como se organizou institucionalmente o Distrito Federal no território carioca tem relação direta com o fato de, na segunda metade dos anos 1950, as reflexões e proposições sobre os rumos e estratégias para a cidade do Rio de Janeiro, após transferência da capital, ocorrerem de forma bastante pobre, e com muito pouca sensibilização social a partir de 1960, sem que se atentasse imediatamente para os impactos e consequências desse processo para o Rio de Janeiro.

A esse respeito, cabe destacar que a transferência da capital para Brasília já estava definida na Constituição desde 1891, permanecendo durante anos como "letra morta". Isso fez com que a proposta lançada por Juscelino Kubitschek, durante sua campanha presidencial e quando assume o governo federal, tenha sido tratada com desdém por diversos setores da sociedade. Mesmo a UDN, partido de oposição, votou todas as leis, propostas por JK, que visavam permitir a criação de Brasília. O objetivo era,

\footnotetext{
${ }^{10}$ Sobre o assunto, ver Osorio (2005). Para uma discussão sobre o conceito de clientela, ver Diniz (1982).
} 
posteriormente, desmoralizar JK, afirmando que a UDN tinha aprovado todas as solicitações do presidente para a construção de Brasília, mas que ele não cumprira a promessa de transferir a capital (sobre o assunto, ver depoimento de Luiz Alberto Bahia, anexo à tese de doutorado de Mauro Osorio (2004)). A descrença quanto à mudança da capital levou também a que ocorresse apenas um único debate público sobre os rumos do Rio após a transferência para Brasília, este organizado pelo jornal Correio da Manhã, em 1958, compreendendo várias entrevistas com líderes empresariais, comunitários, intelectuais e políticos, em uma série denominada "O que será do Rio". ${ }^{11}$

No mesmo sentido que na cidade do Rio de Janeiro, no antigo Estado do Rio de Janeiro a presença da capital se fazia sentir, conforme mostra Marieta de Moraes Ferreira (1991), quando pontua a existência de uma dificuldade de interlocução entre as elites econômicas escravagistas da Velha Província e as elites políticas, de viés mais nacional, como Alberto Torres e Nilo Peçanha, o que teria obstacularizado a implantação de estratégias econômicas quando da decadência da cafeicultura na região, ao longo da segunda metade do século XIX. A questão das elites políticas do antigo Estado do Rio terem um marcante viés nacional apresentará continuidade, em nosso entendimento, até os anos 50, o que se evidencia na presença de personagens como Macedo Soares, Prado Kely, Raul Fernandes e mesmo Amaral Peixoto, que migra da política carioca para a do antigo Estado do Rio, a partir de seu relacionamento com Getúlio Vargas, mas mantém participação e influência na política carioca. ${ }^{12}$ Cabe ressaltar que a importância da articulação entre as elites políticas e econômicas de uma região, para a alavancagem de um processo de desenvolvimento econômico, é bem pontuada em Otávio Dulci (1999), quando o autor analisa essa articulação como um elemento-chave da estratégia engendrada em Minas Gerais, a partir da década de 1940 e 1950, que gerou um articulado arcabouço institucional de fomento ao desenvolvimento daquele estado. ${ }^{13}$

A dificuldade de interlocução entre as elites econômicas e políticas na Velha Província certamente contribuiu para que a lógica econômica na região, pós-ciclo cafeeiro, viesse a depender de investimentos federais e da capital da República, tanto ou mais do que

\footnotetext{
${ }^{11}$ A série referida também se encontra disponível no anexo da tese de doutorado de Mauro Osorio (2004).

${ }^{12}$ Sobre o peso da participação de Amaral Peixoto nas negociações sobre a nova institucionalidade carioca, quando da transferência da capital, ver, por exemplo, Motta (2000:32).

${ }^{13}$ Em Minas Gerais, visando fomentar o desenvolvimento regional e realizar pesquisas, criou-se um conjunto de instituições, incluindo: a Fundação João Pinheiro, voltada para a realização de pesquisas sobre a realidade mineira; um programa de Mestrado, e mais recentemente de Doutorado, denominado CEDEPLAR e vinculado à Universidade Federal de Minas Gerais; a Fundação INDI, órgão para a promoção econômica de Minas Gerais; e o Banco de Desenvolvimento Econômico de Minas Gerais - BDMG.
} 
a própria cidade do Rio de Janeiro. Contribuiu também para que a transferência da capital representasse, no antigo Estado do Rio de Janeiro, da mesma forma que no território carioca, um marco de reversão de dinamismo. ${ }^{14}$

No que se refere à Belacap, ${ }^{15}$ sua trajetória de cidade-capital e a forma como foi historicamente organizada do ponto de vista político-institucional, levou a que na cidade, conforme pontuado por Arnaldo Niskier (Guanabara, 1970:15), a vivência dos problemas nacionais reduzisse "a pálidos reflexos os problemas locais. [Assim,] depois da mudança da capital para o Planalto, o povo carioca descobriu que só conhecia de si mesmo e de sua cidade a visão do turista apressado.”

Esta questão também é apontada em depoimento de Villas-Boas Corrêa ao CPDOC (Ferreira, 1998:55), nos seguintes termos:

Acho que a bancada do Rio de Janeiro, como o Rio era capital, se dissolvia muito, não tinha muita identidade. Até porque o prefeito do Rio era nomeado (...). A grande verdade é a seguinte: cobria-se mal a política carioca, porque a política nacional, que era feita aqui no Rio de Janeiro, abafava a política local.

Assim, nos anos 1960, tendo em vista uma conjunção de fatores, que inclui a história institucional dessa região; o lento processo de transferência da capital; a radicalização vigente na política nacional; e, ainda, a efervescência cultural existente no período - com a emergência da bossa-nova, do cinema novo, CPC da UNE etc. -, fez-se hegemônica a percepção de que o Rio continuaria a ser a Belacap e a capital de fato, o que levou, inclusive, os dois primeiros governos da Guanabara a realizar uma política de modernização urbana, com base no entendimento de que tal política, per se, garantiria a centralidade do desenvolvimento carioca.

Do ponto de vista da formulação de uma política explícita de desenvolvimento econômico - e expressando a falta de massa crítica sobre a realidade local -, desenvolveuse, na Guanabara, nos governos Carlos Lacerda e Negrão de Lima, e com continuidade no governo Chagas Freitas, uma política de fomento focada na indústria, particularmente na organização de distritos industriais, conforme era defendido pela representação patronal da

\footnotetext{
${ }^{14}$ Acreditamos que a Velha Província tenha sofrido com a transferência da capital de forma mais pesada do que a cidade do Rio de Janeiro, não só pela dependência econômica já apontada, mas também pela instabilidade político-institucional vivenciada naquela região, entre 1960 e 1964, após a morte do governador Roberto da Silveira; pela posterior cassação do governador Badger da Silveira; e pelo fato dos governadores nomeados pelo governo militar terem permanecido no cargo, em média, por apenas dois anos.

${ }^{15}$ Como era então chamada a Guanabara, nos anos 1960, em oposição à Novacap (Brasília).
} 
indústria da Guanabara. Tal política realizou-se, fundamentalmente, com base em dados e pressupostos equivocados, sem que se tivesse uma preocupação com o entendimento rigoroso e embasado das potencialidades da região, resultando, ao final da década, em um rotundo fracasso.

A hipótese defendida pela representação patronal da indústria da Guanabara sugeria que, naquela região, da mesma forma que então se dava na cidade de São Paulo e em outras metrópoles mundiais, estaria ocorrendo um derramamento do processo de industrialização, do seu núcleo central para a periferia - tendo em vista o crescimento do porte das indústrias, no auge da segunda revolução industrial -, sendo, portanto, de fundamental importância para a nascente cidade-estado da Guanabara a organização de uma política de oferta de terrenos e de infraestrutura, que retivesse a indústria instalada dentro do território carioca. Apresentou-se, como argumento, o fato de, nos anos 1940, 1950 e início dos 1960, a indústria do antigo Estado do Rio de Janeiro ter crescido acima da média nacional. Porém não se levou em devida consideração que, especificamente na Velha Província, isso não ocorria fundamentalmente pela transferência de plantas industriais privadas da cidade do Rio para o antigo Estado do Rio de Janeiro, mas, sim, pela criação, naquela região, de empresas estatais, pelo governo federal. ${ }^{16}$

Derivou também do pressuposto, existente no início dos anos 1960, de que Brasília não se consolidaria como capital e, por esse motivo e com a modernização da Belacap, o setor serviços tenderia a se manter na Cidade Maravilhosa, não demandando por políticas específicas de fomento. $^{17}$

Tal pressuposto e o foco econômico dos três governos do Estado da Guanabara, entre 1960 e 1974, no setor industrial e em uma política de distritos industriais - inclusive, para tanto, sendo constituída, no início do governo Lacerda, uma empresa de fomento chamada Companhia Progresso da Guanabara (COPEG) -, corresponderam aos interesses

\footnotetext{
${ }^{16}$ Sobre o assunto, ver Silva (2005). Vale pontuar que a carência de reflexão e organização de dados no âmbito regional e a tradição do Rio de Janeiro de privilegiar o debate de temas nacionais e internacionais fazem com que, em diversos momentos, ao ser observada a existência de uma determinada tendência nas principais regiões do planeta, e ao primeiro dado que aponte que aparentemente o mesmo estaria ocorrendo em nossa região, passemos a trabalhar com a mesma hipótese. Isso aconteceu quando da implantação da política de distritos industriais na Guanabara e, mais recentemente, com alguns autores apontando uma significativa interiorização da economia fluminense. No segundo caso, não se levou devidamente em conta que o crescimento do PIB no interior fluminense derivava centralmente da extração de petróleo em alto mar, não tendo gerado uma significativa estrutura produtiva em terra, no interior do estado.

${ }^{17}$ Matérias publicadas no jornal $O$ Globo, logo após a mudança da capital para Brasília, mostram o carioca comemorando o acontecimento. A comemoração baseava-se no fato de que, após longos anos, finalmente o Rio poderia eleger o seu governador e que, pela hipótese da não consolidação de Brasília, a cidade manter-seia como a "capital de fato".
} 
da representação industrial carioca (uma das poucas instituições a se inserir de forma organizada no rarefeito debate local, com forte hegemonia), mas, objetivamente, não deram conta da problemática da reinserção estratégica dessa unidade federativa no cenário da economia brasileira.

De fato, verificamos que a política focada em distritos industriais, organizada para a Guanabara, fracassou. No correr do governo Lacerda, só ocorreu a ocupação, por indústrias, de $1 \%$ da área inicialmente prevista para o total dos distritos industriais, na Avenida das Bandeiras e em Santa Cruz (Guanabara, 1970:46). No governo Negrão de Lima, a política de distritos industriais também não obteve resultado significativo, seja pela não ocupação do novo distrito por ele criado, a Fazenda Botafogo, seja pelo Distrito Industrial de Santa Cruz continuar praticamente desocupado.

Da mesma forma, essa política também não apresentou, no período Chagas Freitas, resultados significativos, apesar de, do ponto de vista da estratégia governamental, ter ocorrido uma amplificação de foco. Isso pode ser visto, por exemplo, em depoimento de José Augusto Assumpção Brito (apud Silva, 2005, Conclusão), segundo o qual a consolidação dos investimentos de infraestrutura que permitem ao Distrito Industrial de Santa Cruz vir a funcionar de fato só ocorreria ao final do governo Chagas Freitas. Além disso, de acordo com Assumpção Brito, a política de distritos industriais não teria importância significativa no crescimento industrial carioca ocorrido nos anos 1970, que, segundo ele, teria derivado centralmente do milagre econômico. ${ }^{18}$ Por outro lado, a partir da análise dos documentos Economia Industrial do Novo Estado do Rio de Janeiro (Barros, 1975) e Tendências de crescimento da Guanabara (Ideg, 1974), é possível chegar à mesma conclusão. De acordo com Barros, por exemplo, no ano de 1973 existiria, para o total do bairro de Santa Cruz, apenas 15 indústrias, representando uma participação no total do número de estabelecimentos de $0,6 \%$. Além disso, o autor analisa que o bairro de Jacarepaguá, onde Chagas Freitas estabeleceu um novo distrito industrial, possuiria, em 1973, apenas $1,83 \%$ do total de estabelecimentos industriais existentes na cidade do Rio de Janeiro (Barros, 1975:156).

\footnotetext{
18 José Augusto Assumpção Brito apresenta longa trajetória de atuação como técnico e dirigente em instituições vinculadas à economia da Guanabara e do antigo Estado do Rio de Janeiro. Nos anos 1960, trabalhou como técnico na COPEG. Na primeira metade dos anos 1970, atuou vinculado à Companhia de Desenvolvimento Industrial do antigo Estado do Rio de Janeiro. A partir de 1974, com a fusão, dirigiu a CODIN, companhia de desenvolvimento do novo Estado do Rio de Janeiro, por um período de dez anos. Posteriormente, participou dos governos Saturnino Braga, Moreira Franco e Marcelo Alencar, tendo sido ainda, no início dos anos 1990, presidente do Sebrae nacional.
} 
Dessa forma, nenhum dos três governos da Guanabara conseguiu articular uma reversão do processo de "bifurcação" - utilizando a conceituação de Paul Krugman (2002) - que ocorreu em 1960, no território carioca.

Por sua vez, após a fusão da Guanabara com o antigo Estado do Rio, em 1974, os governos persistiram em, por um lado, apresentar uma visão equivocada sobre quais deveriam ser as estratégias de desenvolvimento econômico para a região - no governo Faria Lima, por exemplo, a preocupação centrou-se no setor agrícola, apesar da diminuta participação desse setor no PIB carioca. Por outro lado, adotaram um foco pontual, sem estudos setoriais e uma adequada estratégia e coordenação de políticas. Ou, ainda, simplesmente dispensaram a formulação de quaisquer políticas de desenvolvimento econômico.

Para uma análise sobre a inexistência de uma adequada estratégia de desenvolvimento econômico para a cidade do Rio de Janeiro, e posteriormente para o Estado do Rio de Janeiro, acreditamos ser interessante citar a seguinte consideração de Raphael de Almeida Magalhães, vice-governador do primeiro governo da Guanabara e coordenador do Programa de Ações Federais no Rio de Janeiro, no correr dos dois governos de Fernando Henrique Cardoso:

\begin{abstract}
A criação do Estado da Guanabara em si mesma não poderia dar conta das causas que determinaram a decadência da cidade. Teve entretanto o mérito de permitir a autonomia política da cidade, cujo governo pôde, com verdadeiro empenho, tentar, ao menos, recuperar a qualidade dos serviços básicos, enfrentando, com êxito parcial, alguns dos mais agudos problemas de infraestrutura herdados da época da dominação federal.

A verdade é que a simples autonomia política não bastava para a viabilização de um projeto de restauração substitutiva da base produtiva da cidade e da sua região, afetada com a perda irreversível da condição de metrópole nacional. (...)

Redescobrir funções reorganizadoras das atividades econômicas continua sendo, assim, desde a década dos 50, o verdadeiro desafio para a cidade e sua região. Identificá-las, agora, se inscreve, além do mais, no complexo contexto de nosso tempo, que deve considerar a globalização da economia e a necessidade vital de nova forma de articulação do Brasil com os centros decisórios internacionais. (Magalhães, 2001:4-5)
\end{abstract}

Assim, entendemos que a trajetória econômica pós-1960 do Rio de Janeiro foi decisivamente influenciada pela transferência da capital para Brasília; pela história de capitalidade da cidade do Rio; pela constituição de seu desenho político-institucional local; e pela consequente carência de reflexão e equívocos nas estratégias regionais. Além disso, a cidade e o Estado do Rio de Janeiro sofreram uma profunda degradação em sua lógica 
política, a partir do golpe de 64 e das cassações, que atingiram com particular gravidade a cidade do Rio.

De fato, pela centralidade política do Rio de Janeiro, no cenário brasileiro, a sua representação federal foi fortemente atingida no processo de cassações. A polarização existente no debate político nacional e o papel central do Rio nesse debate, principalmente nos anos 1950 e na primeira metade dos anos 1960, redundaram em que a representação federal da cidade apresentasse a marca da radicalização e que se circunscrevesse a poucos partidos, basicamente o PTB e a UDN.

Assim, logo após o golpe de 64, por um lado, o PTB e a esquerda como um todo sofreram pesadamente o processo de cassações, sendo que, no caso da cidade do Rio, entre os dez deputados federais eleitos pelo PTB, em 1962, oito foram cassados. Por outro lado, pelo fato de Carlos Lacerda romper com o regime militar no correr da década de 1960, a UDN carioca, também, foi fortemente atingida, provocando-se, no conjunto, uma desarticulação da lógica nacional nessa região e abrindo-se espaço para que Chagas Freitas, a lógica local e a política de clientela conquistassem uma particular hegemonia, primeiro na cidade, e posteriormente no Estado do Rio. ${ }^{19}$ Essa lógica "fez história" ao longo dos anos, conforme podemos verificar pela declaração da governadora Rosinha Garotinho, publicada no jornal $O$ Globo, de 10 de outubro de 2003, em que ela analisa que, na região fluminense, após o chaguismo e o brizolismo, "por que não o garotismo?”.

Ou seja, na cidade do Rio de Janeiro e, posteriormente, no novo Estado do Rio viria a ocorrer, através dos processos históricos de permanências e mudanças, a coexistência de uma lógica nacional cada vez mais inorgânica com uma lógica clientelista e fragmentária crescentemente hegemônica no plano estadual. Tal realidade gera um marco institucional que desestrutura com particularidade o poder público na região e dificulta a organização consistente de estratégias e políticas regionais. ${ }^{20}$

Assim, a transferência da capital para Brasília, em 1960, e sua consolidação a partir da década de 1970; a carência de reflexão e de adequadas estratégias regionais de fomento ao desenvolvimento; ao lado da particular degradação política que a cidade e o Estado do Rio sofreram em consequência do golpe de 64 são fatores absolutamente centrais no

\footnotetext{
${ }^{19}$ Sobre o assunto ver Silva (2005).

${ }^{20}$ Sobre o assunto, ver a dissertação de mestrado de Maria Helena Versiani (2007). Nessa dissertação, é feita uma análise dos posicionamentos da bancada federal de representação da cidade do Rio de Janeiro, nos anos de 1962 e de 1970. Os discursos da bancada eleita em 1962 eram hegemonicamente referenciados no debate brasileiro. Já os discursos da bancada federal eleita em 1970, tendo em vista as cassações ocorridas, apresentavam uma linha de defesa de questões pontuais e clientelistas.
} 
particular processo de degradação econômico-social do atual Estado do Rio de Janeiro, no cenário brasileiro.

Do ponto de vista econômico, isso pode ser verificado a partir de um conjunto de indicadores. Através das Contas Regionais do Brasil, divulgadas pelo IBGE, por exemplo, entre 1970 e 2010, o PIB do atual Estado do Rio de Janeiro passou de uma participação no PIB nacional de $16,7 \%$ para uma participação de $10,8 \%$, a maior perda entre todas as unidades federativas brasileiras. ${ }^{21}$

Na mesma linha, de acordo com dados do Ministério do Trabalho (RAIS/MTE), o Estado do Rio de Janeiro apresentou, entre 1985 e 2011, o menor crescimento de empregos formais, entre todas as unidades federativas brasileiras. ${ }^{22}$

A particular estagnação do conjunto da economia carioca e fluminense evidencia-se também no fato de que o Estado do Rio de Janeiro, que apresentava, em 1985, a segunda posição, entre todas as unidades federativas brasileiras, no que tange ao número de empregos formais gerados no conjunto das atividades públicas e privadas, estando atrás apenas de São Paulo, tenha sido, em 2011, ultrapassado por Minas Gerais, caindo para a terceira posição no ranking das unidades federativas.

No que se refere ao emprego especificamente na indústria de transformação, a perda foi ainda mais acentuada, o Rio de Janeiro passando da segunda posição, em 1985, para a sexta posição, em 2011, sendo ultrapassado por Minas Gerais, Rio Grande do Sul, Paraná e Santa Catarina. Igualmente expressivo é o fato de Minas Gerais ter ultrapassado o Estado do Rio de Janeiro, em 2004, no que diz respeito à receita gerada pelo imposto estadual de ICMS. ${ }^{23}$

\footnotetext{
${ }^{21}$ Em 1974, como sabemos, ocorreu a fusão entre a Guanabara e o antigo Estado do Rio de Janeiro. Dessa forma, nos dados de PIB aqui apresentados, referentes ao ano de 1970, estão somados o PIB do antigo Estado do Rio de Janeiro com o PIB da Guanabara, permitindo a comparação com o PIB do Estado do Rio pósfusão.

${ }^{22}$ Neste caso, analisamos apenas o período entre 1985 e 2011, por se tratar da série mais longa da RAIS/MTE com a mesma metodologia. Nesse período, o crescimento do emprego formal, público e privado, no total de atividades, no Estado do Rio de Janeiro, foi de apenas 62,7\%, contra um crescimento no Brasil de $126,0 \%$.

${ }^{23}$ Este dado foi calculado a partir de indicadores sistematizados pelo Conselho Nacional de Política Fazendária do Ministério da Fazenda (CONFAZ), nas pesquisas realizadas pelo Observatório de Estudos sobre o Rio de Janeiro, grupo de pesquisa cadastrado no CNPQ e vinculado ao Programa de Pós-Graduação em Direito da Universidade Federal do Rio de Janeiro.
} 


\section{Mudanças e permanências no ERJ, em período recente}

No início do século XXI, a economia do Estado do Rio de Janeiro volta a apresentar, após décadas, uma aproximação com a trajetória da economia brasileira. Isto tem relação com a atração de investimentos para a região, que se inicia em meados dos anos 1990 e que começa a impactar os indicadores econômicos em meados dos anos 2000. Entre os grandes investimentos que têm lugar no Estado do Rio de Janeiro, destacam-se, por exemplo, a chegada de montadoras de automóveis ao Médio Paraíba; a implantação da Rio Polímeros, em Duque de Caxias, objetivando a criação na região de um polo de gásquímico; ${ }^{24}$ a reativação da indústria naval; a ampliação de investimentos pela Petrobras; a instalação, na cidade do Rio de Janeiro, de novas empresas petrolíferas; a consolidação do parque tecnológico da UFRJ, em torno do complexo de petróleo e gás; a instalação de uma planta siderúrgica no distrito industrial de Santa Cruz; além dos investimentos derivados da política de atração de megaeventos.

No entanto, o Estado do Rio de Janeiro ainda apresenta importantes passivos socioambientais e desafios do ponto de vista de uma maior disseminação da geração de emprego e renda na região. Um exemplo evidencia-se a partir de dados do Censo de 2010, do IBGE, que mostram que, em diversas regiões da cidade do Rio, principalmente em áreas periféricas, existe um percentual expressivo de jovens, entre 18 e 24 anos de idade, que não estudam nem trabalham. Na Zona Suburbana, esse percentual chega a ser de $38,8 \%$ na área do Jacarezinho; de 32,9\% no Complexo do Alemão; de 32,5\% na Penha; de 30,1\% em Anchieta; de 30,0\% na Pavuna; e de 29,5\% na Maré. Na Zona Oeste, atinge 38,4\% em Santa Cruz; 35,1\% em Bangu; e 33,0\% em Guaratiba.

No campo social, do ponto de vista educacional, os últimos resultados do Índice de Desenvolvimento da Educação Básica (IDEB/MEC), relativos ao ano de 2011 (últimos dados disponíveis), mostram que o ensino público médio no Estado do Rio de Janeiro está

\footnotetext{
${ }^{24}$ No ano de 1995, o governo Fernando Henrique Cardoso, em face da decadência econômico-social do Estado do Rio de Janeiro e da importância social e simbólica dessa região, criou um Conselho de Ações Federais no estado, presidido pelo presidente da República e tendo como secretário executivo o advogado Raphael de Almeida Magalhães. Esse Conselho definiu, entre suas prioridades: a criação de um polo petroquímico com base no gás natural, em Duque de Caxias; o desenvolvimento de um porto de contêiner, em Itaguaí, cujo projeto era ser o maior porto da América Latina; e a criação de um grupo de trabalho para atuar em prol da conquista, pelo Rio de Janeiro, da função de sede das Olimpíadas de 2004. Essa iniciativa contribuiu para a política de atração de megaeventos, que redundou no Rio de Janeiro ser a sede dos Jogos Panamericanos, em 2007; dos Jogos Mundiais Militares, em 2011; da Rio+20, em 2012; da Jornada Mundial da Juventude, em 2013; uma das principais sedes da Copa do Mundo, de 2014; e também sediar as Olimpíadas de 2016.
} 
apenas na $15^{\mathrm{a}}$ posição, entre todas as unidades federativas brasileiras (embora já tenha apresentado uma melhoria significativa, pois em 2009 estava na $26^{\text {a }}$ posição). Na mesma direção, o Índice de Desenvolvimento do Sistema Único de Saúde (IDSUS), para o ano de 2011, divulgado pelo Ministério da Saúde com base nos dados do DATASUS, mostra Santa Catarina, Paraná, Rio Grande do Sul e Minas Gerais nas quatro primeiras posições, no cenário federativo; o Estado de São Paulo na sétima; e o Estado do Rio de Janeiro apenas na vigésima-quinta posição.

Especificamente em relação à Região Metropolitana do Rio de Janeiro, o conjunto de indicadores aponta, para o período pós-1960, uma particular degradação de sua periferia, no cenário das metrópoles existentes na Região Sudeste. Organizando-se, por exemplo, um ranking dos resultados do IDEB/MEC para a educação básica pública, no ano de 2011, verifica-se que entre os 57 municípios das periferias das Regiões Metropolitanas do Rio de Janeiro (RMRJ), São Paulo (RMSP) e Belo Horizonte (RMBH), dos 18 piores resultados, 16 são ocupados pelos municípios da periferia da RMRJ.

Outra evidência são os dados do Censo do IBGE de 2010 relativos ao transporte público, que mostram uma situação na periferia da RMRJ pior do que a verificada na periferia da RMSP. ${ }^{25}$ De acordo com esses dados, enquanto, na periferia da RMRJ, 32,41\% dos moradores levam mais de uma hora por locomoção efetuada, na periferia da RMSP, esse percentual é de $25,50 \%$.

No âmbito do Estado do Rio de Janeiro como um todo - e, vale enfatizar, como consequência de sua trajetória pós-1960 -, os indicadores sociais e de infraestrutura também apontam uma particular degradação da região no cenário federativo. Dados do Censo do IBGE de 2010 mostram, por exemplo, uma situação particularmente grave do ponto de vista habitacional. Assim, organizando-se um ranking, por estado brasileiro, do percentual de pessoas moradoras de favelas, em relação ao total de habitantes, verifica-se que o Estado do Rio de Janeiro apresentou, em 2010, um percentual de 12,7\%, o terceiro maior entre todas as unidades federativas, melhor apenas do que o Pará e o Amapá que apresentavam, respectivamente, o primeiro e segundo maior percentual. Este era de 6,62\% no Estado de São Paulo e de apenas 3,07\% em Minas Gerais.

A trajetória do Estado do Rio de Janeiro no pós-1960 também conduziu a uma situação particularmente grave no que tange à questão da segurança pública, com a

\footnotetext{
${ }^{25}$ Considera-se aqui como periferia das três regiões metropolitanas apontadas todos os municípios nelas localizados, excetuando-se as suas respectivas capitais estaduais.
} 
constituição de "estados paralelos" na metrópole carioca, em um nível de institucionalização inexistente em outras metrópoles brasileiras e mesmo da América Latina, que surge como consequência de uma particular desestruturação ocorrida na polícia fluminense com a instauração do marco institucional que passa a existir no Rio após o golpe de 1964.

Sobre esse segundo aspecto, vale citar dois artigos analíticos: o de Mauro Osorio da Silva, intitulado Estado do Rio de Janeiro: estagnação de longo curso e possibilidades de reversão, publicado no Jornal dos Economistas, do CORECON/RJ, em 2008, e o do jornalista Xico Vargas, intitulado O caminho de ouro, publicado no site No Mínimo, em 2006.

No primeiro, tem destaque o fato de policiais de outros estados brasileiros incluindo estados muito violentos, como Pernambuco -, que vieram para o Rio de Janeiro compor a Força Nacional, por ocasião do Panamericano em 2007, terem, de acordo com matérias de jornais à época, ficado estupefatos com o nível de armamento verificado em áreas dominadas pelo tráfico no Rio, bem como com o elevado grau de rejeição dos moradoras de favelas em relação às forças policiais estaduais.

No segundo artigo, Xico Vargas aponta o alarmante nível de institucionalização da corrupção então verificada na estrutura de segurança pública estadual. Diz ele: "De qualquer maneira, para policiais (os da banda boa) não há dúvida de que todas as delegacias têm dono e quotas de arrecadação".

\section{Desafios para o século XXI}

A gravidade dos indicadores referentes à trajetória do Estado do Rio de Janeiro, apontados neste artigo, só pode ser bem compreendida, a nosso ver, considerando-se o conjunto das razões apresentadas. Ou seja, a trajetória do ERJ deriva de uma convergência de questões, que são: 1) a transferência da capital para Brasília, em 1960; 2) a não construção de adequadas estratégias de fomento ao desenvolvimento econômico-social, que dessem conta da nova realidade que se estabelece para a região com a mudança da capital - o que, em boa medida, é fruto da carência (mesmo até os dias atuais) de reflexões regionais no âmbito do Estado do Rio de Janeiro; e 3) o marco político-institucional 
constituído historicamente no Rio, que sofrerá uma particular desestruturação a partir do golpe de 64 e das cassações.

É importante observar, contudo, que, a partir de 2006, começam a existir iniciativas, no âmbito da política pública do Estado do Rio de Janeiro, que, ao lado dos investimentos que chegam à região, contribuem para a possibilidade de reversão de sua trajetória de decadência. Nessa direção, por exemplo, podem ser situadas as ações tomadas no âmbito da Secretaria Estadual de Segurança Pública, para combater a corrupção, no nível em que se havia institucionalizado, e a política de implantação das Unidades de Polícia Pacificadora. No âmbito da Secretaria Estadual de Fazenda, tem destaque o esforço de modernização levado a termo, com o retorno à prática de concursos públicos (inexistentes desde os anos 1980) e uma maior transparência na gestão fiscal. No que se refere à Secretaria Estadual de Planejamento e Gestão, ocorre uma descentralização orçamentária e a modernização da área de gestão dos servidores estaduais, que até então funcionava com base em um antiquado sistema de informática implantado nos idos dos anos 1970. Na Secretaria Estadual de Desenvolvimento Econômico, ocorre o fortalecimento da agência estadual de fomento (AgeRio) e a reestruturação da Junta Comercial, que teve em torno de $1 / 4$ de seus funcionários demitidos, aparentemente por razões relacionadas à falta de moralidade na gestão pública, e que, em governos anteriores, chegou a financiar até concurso de miss! Por fim, vale mencionar o início da organização de concursos públicos em algumas áreas da administração estadual, também inexistentes há anos, sendo que o Detran-RJ, por exemplo, realizou, recentemente, o primeiro concurso público de toda a sua história. ${ }^{26}$

No entanto, do ponto de vista do estabelecimento de uma rotina de planejamento e coordenação de políticas, que dê conta, concomitantemente, do pleno aproveitamento das possibilidades existentes no horizonte, a partir do ciclo de investimentos que já chegam ao estado ou previstos, e do enfrentamento dos graves problemas e desigualdades que ainda perduram no campo econômico-social e de infraestrutura no Estado do Rio de Janeiro, os desafios ainda estão, em larga medida, em aberto.

Nesse sentido, a afirmação de uma cultura de planejamento para o desenvolvimento regional é fundamental, devendo-se destacar a importância do papel da academia nesse processo. 
De fato, uma contribuição fundamental poderia ocorrer no âmbito das universidades, por exemplo, através da ampliação de grupos permanentes de pesquisa sobre o Estado do Rio de Janeiro e suas regiões, nas áreas econômica, social e institucional, e da organização de bases de dados e de seminários e publicações. ${ }^{27}$

Deve-se ressaltar ainda o importante papel que pode ter a realização de pesquisas que levem a um melhor entendimento sobre o ambiente institucional no Estado do Rio de Janeiro, principalmente a partir da transferência da capital para a Brasília e da degradação da lógica político-institucional regional após o golpe de 64. Como lembra Douglass North (1993), um determinado marco político institucional, em determinada região, tende a gerar uma lógica e práticas homogeneizantes, que se generalizam entre os mais diversos atores sociais. Assim, é crucial, no quadro da necessidade de maior reflexão acadêmica local no Estado do Rio de Janeiro, investir também no desenho de linhas de pesquisa referentes à história e à forma de atuação das instituições/organizações vinculadas aos poderes Legislativo e Judiciário do estado, principalmente no período pós-1964. ${ }^{28}$

\section{Referências bibliográficas}

BARROS, Frederico Robalinho de. Economia Industrial do Novo Estado do Rio de Janeiro. Rio de Janeiro: APEC/IDEG, 1975.

BERNARDES, Lysia Maria Cavalcanti (Coord.). O Rio de Janeiro e sua região. Rio de Janeiro: IBGE/Conselho Nacional de Geografia, 1964.

BRASILEIRO, Ana Maria. A fusão: análise de uma política pública. Brasília: IPEA, 1979 (Série Estudos para planejamento - 21).

CAMARGO, Aspásia (Coord.). Artes da política: diálogo com Amaral Peixoto. Rio de Janeiro: Nova Fronteira/Ed. da FGV/CPDOC/UFF, 1986.

CANO, Wilson. Raízes da concentração industrial em São Paulo. 4. ed. Campinas/SP: UNICAMP/IE, 1998.

\footnotetext{
${ }^{26}$ A organização de concursos públicos, no entanto, ainda demanda por maior ousadia, cabendo realizar um debate com a sociedade sobre as funções que devem ser assumidas pelo setor público, adequando-se a estrutura de pessoal concursado em cada área.

${ }^{27}$ A título de exemplo da carência de reflexão regional, no Rio de Janeiro, até os dias atuais, se entrarmos nos sites dos programas de mestrado e doutorado especificamente em Economia existentes na Região Metropolitana do Rio de Janeiro, verificamos que, a despeito dos trabalhos realizados, não existe nenhum grupo de pesquisa permanente nas áreas de Economia Regional e Economia Fluminense.

${ }^{28}$ Sobre este ponto, ver, também, Putnam (1996). Robert Putnam estuda a evolução das diversas regiões da Itália e defende a tese de que as regiões com uma institucionalidade mais transparente, horizontal e com maior participação social apresentam uma vida social e um dinamismo econômico qualitativamente melhor do que as regiões em que o quadro institucional se sustenta com base em relações mais verticais, menor participação social e maior nível de desconfiança e incerteza entre os cidadãos.
} 
CUNHA, Luiz Roberto. Crise econômica: Rio de todas as crises. Rio de Janeiro: IUPERJ, 1990 (Série Estudos e Pesquisa).

DULCI, Otávio Soares. Política e recuperação econômica em Minas Gerais. Belo Horizonte: Ed. da UFMG, 1999.

DINIZ, Eli. Voto e Máquina Política Patronagem e Clientelismo no Rio de Janeiro. Rio de Janeiro: Paz e Terra, 1982.

FERREIRA, Marieta de Moraes (Coord.). Rio de Janeiro: Uma cidade na história. Rio de Janeiro: Ed. da FGV, 2000. . (Coord.). Crônica política do Rio de Janeiro. Rio de Janeiro: Ed. da FGV, 1998.

. Em busca da Idade de Ouro: as elites políticas fluminenses na primeira República (1889-1930). Niterói: UFF. Instituto de Ciências Humanas e Filosofia, 1991.

FIANI, Ronaldo. Estado e economia no institucionalismo de Douglass North. Revista de Economia Política, v. 23, n. 2, abr./jun. 2003.

FREIRE, Américo. Uma capital para a República: poder federal e forças políticas locais no Rio de Janeiro na virada para o século XX. Rio de Janeiro: Revan, 2000.

.; SARMENTO, Carlos Eduardo; MOTTA, Marly Silva da. Um Estado em questão: Os 25 anos do Rio de janeiro. Rio de Janeiro: Ed. da FGV, 2001.

GALBRAITH, John Kenneth. Galbraith Essencial - Os Principais Ensaios de John Kenneth Galbraith. São Paulo: Editora Futura, 2007.

GUANABARA. Secretaria de Ciência e Tecnologia. Comissão do ano 2000. Rio Ano 2000. Rio de Janeiro, 1970.

HIRSCHMAN, Alberto. Estratégia do desenvolvimento econômico. Rio de Janeiro: Fundo de Cultura, 1958.

HODGSON, Geoffrey M. Economia e evolução: o regresso da vida à teoria econômica. Oeiras: Celta, 1997.

HODGSON, Geoffrey M. The Approach of Institutional Economics. Journal of Economic Literature, mar. 1998.

INSTITUTO DE DESENVOLVIMENTO DA GUANABARA. Tendências de crescimento da Guanabara. Rio de Janeiro: SENAI, 1974.

KRUGMAN, Paul. The role of geography in development. International Regional Science Review, [S.1.], vol. 22, n. 2, pp. 142-161, ago. 1999.

- Increasing returns and economic geography. Journal of Political Economy, Chicago, vol. 99, n. 31, 1991.

.; FUJITA, Masahisa; VENABLES, Anthony J. Economia espacial: urbanização, prosperidade econômica e desenvolvimento humano no mundo. São Paulo: Futura, 2002. 
LESSA, Carlos. O Rio de todos os Brasis: uma reflexão em busca de auto-estima. Rio de Janeiro: Record, 2000.

MADISON, James; HAMILTON, Alexander; JAY, John. Os artigos federalistas: 1787/1788. Rio de Janeiro: Nova Fronteira, 1993.

MAGALHÃES, J. P. A. et al. Rio Século XXI: perspectivas e propostas para a economia fluminense. Rio de Janeiro: JB, 1991.

MAGAlHÃES, João Paulo (Coord.). Problemas e potencialidades do estado do Rio de Janeiro. Rio de Janeiro: Instituto de Estudos Político e Sociais/BANERJ, 1983. 8 v.

MAGALHÃES, Raphael de Almeida. Breve Histórico sobre a Estruturação Física e Econômica da Cidade e sua Região. [S.1.: s.n.], 2001. Texto mimeografado.

MELLO, João Manuel Cardoso de. O capitalismo tardio. São Paulo: Brasiliense, 1982.

MELO, Luiz Martins de. Sistemas locais de inovação: o caso do Rio de Janeiro. In: CASSIOLATO, José Eduardo; LASTRES, Helena M.M. Globalização \& inovação localizada. Brasília: IBICT/MCT, 1999.

MOTTA, Marly Silva da. Rio de Janeiro: de cidade-capital a Estado da Guanabara. Rio de Janeiro: ALERJ, 2001.

. Saudades da Guanabara. Rio de Janeiro: Ed. da FGV, 2000.

MOULAERT, Frank. Globalization and integrated area development in European cities. Nova Iorque: Oxford University Press, 2000.

MYRDALL, Gunnar. Teoria econômica e regiões subdesenvolvidas. 2. ed. Rio de Janeiro: Saga, 1968.

NATAL, Jorge L. Inflexão econômica positiva e dinâmica regional. In: NATAL, Jorge L. (Org.). O Estado do Rio de Janeiro pós-1995: dinâmica econômica. Rede urbana e questão social. Rio de Janeiro: Faperj-Pubblicati, 2005. pp.43-61.

NORTH, Douglass C. Instituciones, cambio institucional y desempeño económico. México: Fondo de Cultura Económica, 1993.

OSORIO, Mauro. Características e evolução recente do emprego e da economia carioca e metropolitana. Abril de 2011 (Coleção Estudos Cariocas/IPP-Rio).

. Rio nacional, Rio local: mitos e visões da crise carioca e fluminense. Rio de Janeiro: SENAC, 2005.

Rio nacional, Rio local: origens e especificidades da crise carioca e fluminense. Estratégias, Instituições e Desenvolvimento. Tese de Doutordado. Rio de Janeiro: Universidade Federal do Rio de Janeiro/Instituto de Planejamento Urbano e Regional da Universidade Federal do Rio de Janeiro, 2004.

.; SOBRAL, Bruno Leonardo B.; CORDEIRO, Orlando Thomé; CARVALHO, Guilherme; FILGUEIRAS, Marcos. Análise da dinâmica espacial dos complexos logísticos-produtivos e recomendações para o maior impacto positivo dos 
empreendimentos estruturantes. Plano Diretor Estratégico de Desenvolvimento Sustentável da Meso-Região do Arco Metropolitano do Rio de Janeiro (Relatório Final da Política de Desenvolvimento Econômico e Social - PDES). Rio de Janeiro: Governo do Estado do Rio de Janeiro, 2011.

PACHECO, Carlos Américo. Fragmentação da nação. São Paulo: UNICAMP/IE, 1998.

PERROUX, François. A economia do século XX. Trad. José Lebre de Freitas. Lisboa: Herder, 1967.

PUTNAM, Robert D. Comunidade e democracia: a experiência da Itália moderna. Rio de Janeiro: Ed. da FGV, 1996.

ROSA, Luiz Pinguelli (Coord.); OSORIO, Mauro (Subcoord.). O gás natural na América Latina, no Brasil e no Estado do Rio de Janeiro: algumas considerações. Cadernos de Energia n. 8; Rio de Janeiro: ENERGE/COPPE/UFRJ, JUNHO/1995.

ROVERE, Renata Lèbre La; SILVA, Mauro Osorio da (Orgs.). Desenvolvimento econômico local da Zona Oeste do Rio de Janeiro e seu entorno. Rio de Janeiro: PoD, 2010.

SANTOS, Angela Moulin S. Penalva. Planejamento e desenvolvimento. O Estado da Guanabara. 1990. Tese de Doutorado em Arquitetura e Urbanismo. São Paulo: Universidade de São Paulo, 1990.

SARMENTO, Carlos Eduardo. O espelho partido da metrópole - Chagas Freitas e o campo político carioca (1950-1983): liderança, voto e estruturas clientelistas. Tese de Doutorado. Rio de Janeiro: IFCS/UFRJ, 2002.

(Org.). Chagas Freitas: Perfil Político. Rio de Janeiro: Ed. da FGV; ALERJ, 1999. pp. 135-165.

SCHWARTZMAN, Jacques (Org.). Economia Regional: textos escolhidos. Belo Horizonte: CEDEPLAR/CETREDE-MINTER, 1977.

SOBRAL, Bruno Leonardo Barth. Ciclo de investimentos e o papel das estratégias de grandes agentes econômicos: o caso da periferia da Região Metropolitana do Rio de Janeiro - 1995-2010. Tese de Doutorado. Campinas: Universidade Estadual de Campinas/Instituto de Economia, 2012.

- A desconcentração produtiva regional no Brasil: análise do caso do estado do Rio de Janeiro - 1970/2005. Dissertação de Mestrado. Campinas: Universidade Estadual de Campinas/Instituto de Economia, 2007.

VEBLEN, Thorstein. The Theory of the Leisure Class. New York: Modern Library, 1934.

VERSIANI, Maria Helena. Padrões e práticas na política carioca: os deputados federais eleitos pela Guanabara em 1962 e 1970. Dissertação de Mestrado. Rio de Janeiro: Universidade Federal do Rio de Janeiro/Instituto de Filosofia e Ciências Socais/ Programa de Pós-Graduação em História Social, 2007. 